\title{
British Thoracic Society Clinical Statement on Pulmonary Arteriovenous Malformations
}

\author{
Claire L Shovlin, ${ }^{1,2}$ Robin Condliffe, ${ }^{3}$ James W Donaldson, ${ }^{4}$ David G Kiely, ${ }^{3,5}$ \\ Stephen J Wort, ${ }^{6,7}$ on behalf of the British Thoracic Society
}

${ }^{1} \mathrm{NHLI}$ Vascular Science, Imperial College London, London, UK ${ }^{2}$ Respiratory Medicine, and VASCERN HHT European Reference Centre, Hammersmith Hospital, Imperial College Healthcare NHS Trust, London, UK

${ }^{3}$ Pulmonary Vascular Disease Unit, Royal Hallamshire Hospital Sheffield, UK

${ }^{4}$ Dept of Respiratory Medicine, Derby Teaching Hospitals NHS Foundation Trust, Derby, UK

${ }^{5}$ Department of Infection, Immunity and Cardiovascular Disease, University of Sheffield, Sheffield, UK

${ }^{6}$ Pulmonary Hypertension Department, Royal Brompton Hospital, London, UK

${ }^{7} \mathrm{NHLI}$ Vascular Science, Imperial College London, London, UK

\section{Correspondence to}

Professor Claire L Shovlin, Professor of Practice (Clinical and Molecular Medicine), NHLI Vascular Science, Imperial College London, Imperial Centre for Translational and Experimental Medicine, Hammersmith Campus, Du Cane Rd, London W12 ONN, UK; C. shovlin@imperial.ac.uk

Received 14 July 2017 Revised 1 September 2017 Accepted 4 September 2017

\section{EXECUTIVE SUMMARY}

Pulmonary arteriovenous malformations (PAVMs) are structurally abnormal vascular communications that provide a continuous right-to-left shunt between pulmonary arteries and veins. Their importance stems from the risks they pose (>1 in 4 patients will have a paradoxical embolic stroke, abscess or myocardial infarction while life-threatening haemorrhage affects 1 in 100 women in pregnancy), opportunities for risk prevention, surprisingly high prevalence and underappreciation, thus representing a challenging condition for practising healthcare professionals. The driver for the current Clinical Statement was the plethora of new data since previous hereditary haemorrhagic telangiectasia (HHT) guidelines generated in 2006 and a systematic Cochrane Review for PAVM embolisation in 2011. The British Thoracic Society (BTS) identified key areas in which there is now evidence to drive a change in practice. Due to the paucity of data in children, this Statement focused on adults over 16 years. The Statement spans the management of PAVMs already known to be present (interventional and medical), screening and diagnosis (for PAVMs and HHT) and follow-up of patients following a first diagnosis, intervention or negative screen for PAVMs. The Good Practice Points (in bold) were generated for a target audience of general respiratory, medical and specialist clinicians and were approved by the BTS Standards of Care Committee, before formal peer review and public consultation. The Statement spans embolisation treatment, accessory medical management and issues related to the likelihood of underlying HHT.

\section{INTRODUCTION}

Pulmonary arteriovenous malformations (PAVMs) are structurally abnormal vascular communications between pulmonary arteries and veins that range in size and complexity and provide an anatomic right-to-left shunt. ${ }^{1-4}$ PAVMs allow a proportion of the right ventricular stroke volume to bypass gas exchange, filtration and other functions of the pulmonary capillary bed. Limited prevalence data suggest that PAVMs may affect many as 1 in 2600 individuals (95\% CIs 1 in 1315 to 1 in 5555). ${ }^{5}$ The majority of PAVMs are due to hereditary haemorrhagic telangiectasia (HHT), ${ }^{6-9}$ but there is evidence for underappreciation of both PAVMs ${ }^{10}$ and HHT. ${ }^{11}$ PAVMs may be present from birth and have usually completed major development by adult life, although they can enlarge later in life, for example, during pregnancy or other alterations in pulmonary haemodynamics. ${ }^{12}$ The size of the right-to-left shunt determines the degree of hypoxaemia, ${ }^{13}{ }^{14}$ exuberant ventilation ${ }^{15}$ and high cardiac output. ${ }^{16}$ PAVMs of any size allow paradoxical emboli that may cause ischaemic strokes, ${ }^{17} 18$ myocardial infarction, ${ }^{18-20}$ cerebral (brain) ${ }^{1721-23}$ and peripheral abscesses, discitis and migraines. ${ }^{24-26}$ Less frequently, PAVMs may cause haemoptysis, haemothorax ${ }^{27-29}$ and/or maternal death in pregnancy. ${ }^{29}$ Due to compensatory adaptations, respiratory symptoms are frequently absent or not recognised until PAVM treatment has led to improvement or resolution. ${ }^{13-1626}$ However, at least one in three patients with PAVMs will have more severe migraines, nosebleeds, respiratory, cardiac or other symptoms than they would if PAVMs were treated. Risk-benefit analyses are almost always in favour of treatment. ${ }^{30-32}$ There is evidence for risk reduction for many PAVM complications, ${ }^{13-17} 242629$ although contraindications should be considered. Additionally, recent evidence reminds of the potential levels ${ }^{33}$ and consequences $^{134}$ of iatrogenic radiation exposure incurred in delivery of these health benefits.

HHT, the most common cause of PAVMs, is a multisystemic vascular disorder. ${ }^{6-9}$ HHT is inherited as an autosomal dominant trait and most commonly results from a pathogenic sequence variant in ENG encoding endoglin (HHT type 1/ HHT1), ACVRL1 encoding ALK-1 (HHT type 2/ HHT2) or SMAD4. ${ }^{35-37}$ Frequent nosebleeds are the hallmark of HHT. Approximately 50\% of patients with HHT have CT-detectable PAVMs ${ }^{38}$ and most have systemic arteriovenous malformations (AVMs) in sites such as the liver, gastrointestinal tract or brain. $^{6-9} 35$ 37-39 All HHT genotypes predispose to AVMs, bleeding from mucocutaneous and gastrointestinal telangiectasia, and iron deficiency anaemia due to chronic blood loss. ${ }^{40}$ Visceral AVMs are usually silent but have the potential for site-specific complications. By reducing systemic vascular resistance, visceral AVMs require supranormal cardiac outputs to maintain arterial blood pressure, with cardiac demands increased further by coexisting iron deficiency, anaemia, hypoxaemia, exercise, pregnancy and sepsis. ${ }^{41-46}$ Despite their haemorrhagic phenotype, patients with HHT are at risk of venous thromboemboli (VTE), particularly if serum iron is low ${ }^{47}$ and/or factor VIII high. ${ }^{47}$ Patients with HHT often tolerate anticoagulation or antiplatelet therapy well. ${ }^{49}$ Recently described reduced rates of specific cancers, ${ }^{34} 5051$ better survival outcomes for cancer patients who have $\mathrm{HHT}^{52}$ and low myocardial infarction rates ${ }^{20}$ await explanation. The HHT phenotype is subtly different between HHT genotypes, for instance patients with HHT2 are less likely to have PAVMs and more likely to

Condliffe R, Donaldson JW, 
have hepatic AVMs than patients with HHT1 or SMAD4-related $\mathrm{HHT}^{3739}$ In addition, many rarer HHT complications appear to be relatively genotype specific, for example, pulmonary arterial hypertension $\left(A C V R L 1^{53-55}\right)$, juvenile polyposis $\left(S M A D 4^{37}{ }^{56}\right.$ ) and aortopathy (SMAD $\left.4^{3757}\right)$.

Non-HHT patients can develop sporadic PAVMs, when they are generally solitary. Single and multiple PAVMs commonly occur following surgical treatment of complex cyanotic congenital heart disease if a lung receives no or minimal hepatic venous return ${ }^{58-60}$ and more rarely as part of other inherited vasculopathies. Radiological differential diagnoses of a PAVM include a bronchocoele, bronchopulmonary sequestration, pulmonary varix, pulmonary arterial aneurysm and aberrant systemic to pulmonary communications. ${ }^{2}$ Other causes of rightto-left shunts detectable by contrast echocardiography include intermittent shunting through intracardiac defects (when rightside pressures exceed left, most commonly after a Valsalva manoeuvre $\left.{ }^{61}\right)$, the hepatopulmonary syndrome ${ }^{62}$ and functional shunting (present in $\sim 10 \%$ of the general population at rest, rising on exercise, ${ }^{63}$ after adrenergic stimuli ${ }^{64}$ and in response to low $\mathrm{PaO}_{2}{ }^{65}$ ).

\section{CLINICAL STATEMENT METHODOLOGY}

The Clinical Statement Group (CSG) was chaired by Professor Claire Shovlin (CLS) and comprised the three most recent chairs of the British Thoracic Society (BTS) Pulmonary Vascular Specialist Advisory Group and an experienced respiratory trainee. The CSG identified key areas requiring Good Practice Points. Evidence from manuscripts identified by ongoing practice reviews was supplemented by formal PubMed searches. Proposed Statement content and groupings were agreed and discussed by the committee and assigned to areas of management (figure 1). Following discussions of broad Statement content, the first text draft was written by CLS, and all committee members revised and contributed to further development. The draft Statement was reviewed by the BTS Standards of Care Committee and made available on the BTS website for a limited period of public and key stakeholder consultation (December 2016-January 2017). It was then peer-reviewed for Thorax publication, and the revised document was reapproved by the BTS Standards of Care Committee in June 2017 before final Thorax review and publication.

\section{SECTION 1: INTERVENTIONS}

\section{A: Management overview}

All patients with radiographically-visible PAVMs should be considered for referral to interventional colleagues experienced in PAVM embolisation. Due to the small diameter of many PAVM feeding arteries and the possibility of reperfusion or recanalisation, medical management and follow-up is also required (see Sections 2 and 4).

Embolisation treatment is recommended even for asymptomatic patients. ${ }^{31}$ PAVM treatment reduces risks from paradoxical emboli and improves oxygenation, other physiological parameters, symptoms exacerbated by right-to-left shunting and haemorrhage. ${ }^{13-172426}$ Patients should not undergo embolisation expecting improved exercise tolerance, although this may be observed. Patients with concurrent chronic obstructive pulmonary disease, asthma or cardiovascular disease, or patients pursuing activities when exuberant ventilation is required to clear carbon dioxide, are more likely to note symptomatic benefit from embolisation. ${ }^{1366}$

Right-to-left shunts detectable only by contrast echocardiography carry lower risks, ${ }^{67}$ but for radiologically-visible PAVMs, there is no ' $3 \mathrm{~mm}$ rule' (a widely held view prior to data published in 2006/2007 that stated lesions with a diameter of $<3 \mathrm{~mm}$ did not require interventional therapy ${ }^{68}$ ) or other risk threshold. Complete obliteration of all PAVMs by embolisation is less commonly achieved than shunt reduction, particularly if PAVMs are multiple and associated with HHT. ${ }^{2-4} 1769-73$ Embolisation is a safe intervention in experienced hands with a major complication rate of approximately $1 \% .^{74}$

Treatment decisions should be made in a multiprofessional context, in accordance with patient preference. Patient age, symptoms, potential contraindications ${ }^{2-4} 7576$ and wider screening issues (Section 3) should be taken into consideration. Guidance on technical aspects of embolisation including device

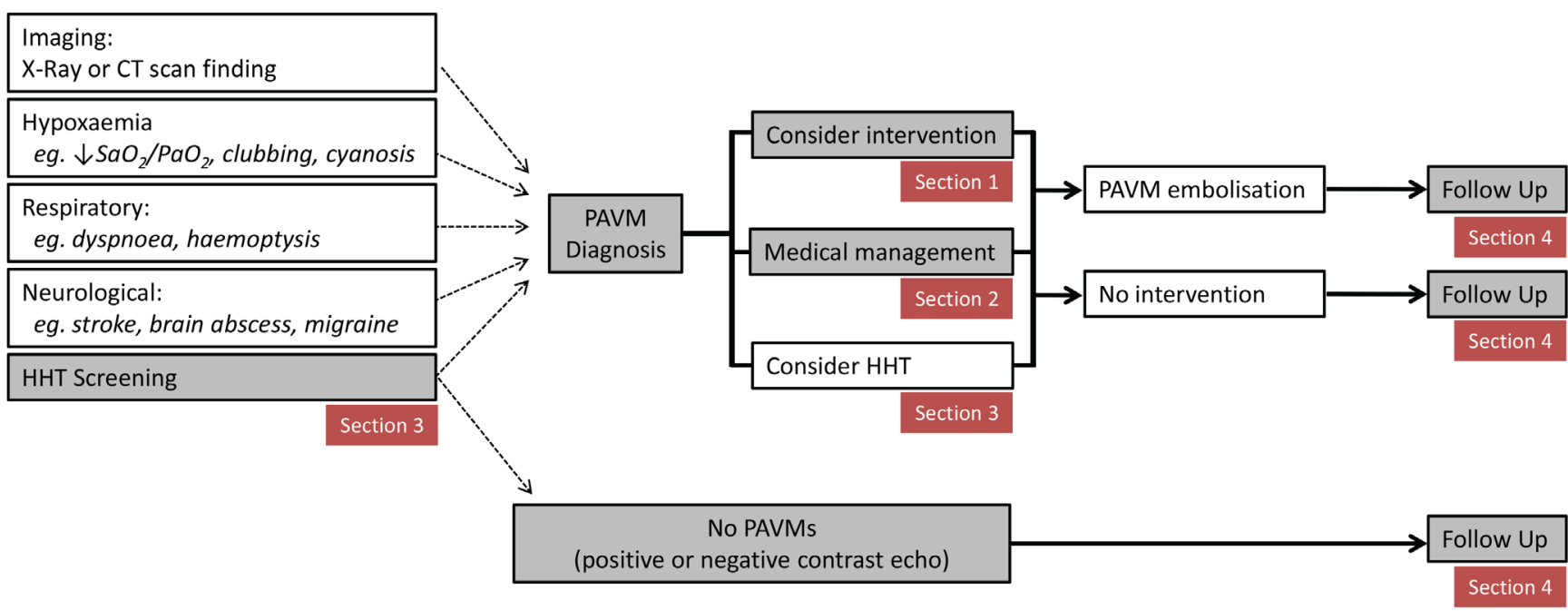

Figure 1 Overview of PAVM management and position of statement sections. HHT, hereditary haemorrhagic telangiectasia; PAVM, pulmonary arteriovenous malformation. $\mathrm{PaO}_{2}$, arterial partial pressure of oxygen. $\mathrm{SaO}_{2}$, oxygen saturation: percentage of haemoglobin binding sites occupied by oxygen. 
choice, placement and operator dependence are provided in interventional manuscripts. ${ }^{2-4}$ 69-72 It is important to note that embolisation should not be undertaken by interventional radiologists unless they have extensive prior experience and work in a high volume PAVM practice-the European Reference Network for Vascular Diseases (VASCERN) defines this as $>20$ procedures. ${ }^{77}$ It is also noteworthy that there are diverse practices even in specialist centres. ${ }^{78}$

\section{B:Possible contraindications to embolisation}

Pregnancy, pulmonary hypertension and renal impairment are relative contraindications to elective embolisation procedures, though benefits may outweigh risks particularly in the setting of life-threatening haemoptysis.

Each relative contraindication is uncommon. Radiation and risks of preterm labour mean that prophylactic treatment of PAVMs in pregnancy is not commonly performed. ${ }^{29}$ It is anticipated that the absence of clinical symptoms and absence of features on imaging performed to evaluate PAVMs will be able to exclude clinically significant pulmonary hypertension. If heart disease, heart failure or pulmonary hypertension are suspected, then ECG and echocardiography (to estimate systolic pulmonary artery pressure and right ventricular size and function) should be performed before discussing with interventional colleagues. For patients with renal failure, the risk of exacerbation by radiological contrast medium should be considered. Rarer contraindications should be considered on merit.

Local policies for periprocedural anticoagulant bridging should be followed, and temporary cessation of antiplatelet therapy (as recommended by interventional colleagues) should be considered if safe.

\section{C:Surgical considerations}

Lung transplantation is not indicated for uncomplicated PAVMs, but there may be a role for limited surgical resection if the PAVMs are unsuitable for embolisation.

Longevity of patients with severe PAVMs exceeds those of lung transplant recipients. ${ }^{17980}$ For patients with ongoing neurological or other PAVM complications, if there is no realistic possibility of further improvement by embolisation and disease is anatomically limited, then surgical resection may be considered.

\section{SECTION 2: MEDICAL MANAGEMENT 2A:Hypoxaemia}

i) Despite oxygenation parameters that would fulfil requirements for supplementary oxygen in other clinical settings, patients with hypoxaemia due to PAVMs usually display good exercise capacity, flight tolerance and successful pregnancies, assuming normal physiological compensations can operate.

Hypoxaemia defined by low $\mathrm{PaO}_{2}$ and low $\mathrm{SaO}_{2}$ results from right-to-left shunting: $\mathrm{SaO}_{2}$ is generally in the region of $60 \%$ for a shunt of $50 \%$ of the cardiac output, $80 \%$ for a shunt of $30 \%$ and $90 \%$ for a shunt of $10 \% .{ }^{118}$ Arterial oxygen content $\left(\mathrm{CaO}_{2}\right)$ is usually preserved by secondary erythrocytosis $\left(\mathrm{CaO}_{2} \approx 1.34 \times \mathrm{SaO}_{2} \times\right.$ haemoglobin $) .{ }^{81}$ In iron-replete patients with PAVMs, the median $\mathrm{CaO}_{2}$ is $\sim 18.8 \mathrm{mls} / \mathrm{dL}$ : the $\mathrm{CaO}_{2}$ is higher in those who exercise vigorously and lower if iron deficiency is present. ${ }^{13} 1473$ Oxygen utilisation/delivery at peak exercise can also be maintained in hypoxaemic patients ${ }^{15}$ whose cardiovascular and haematological compensations regress after successful embolisation. ${ }^{13-16}$ Dyspnoea is uncommon, ${ }^{13} 66$ even in flight, ${ }^{82}$ during exercise ${ }^{14} 1583$ or if $\mathrm{SaO}_{2}$ and $\mathrm{CaO}_{2}$ fall suddenly on standing (orthodeoxia). ${ }^{66}$ Hypoxaemic patients at their limits of compensation more commonly describe dizziness, fatigue, palpitations, angina, or other symptoms as exhibited by anaemic patients. These, or any new respiratory symptoms, should prompt evaluation and treatment of potential concurrent iron deficiency, haematological or cardiorespiratory pathologies limiting compensatory mechanisms, particularly as these non-PAVM pathologies may be more amenable to symptomatic improvement following treatment.

ii) There is no indication for supplementary oxygen, bed rest, exercise limitation, or hospitalisation for the asymptomatic, hypoxaemic patient with PAVMs.

Long-term oxygen therapy in respiratory disease is used to ameliorate alveolar hypoxia. In contrast, there is no alveolar hypoxia in patients with uncomplicated PAVMs. ${ }^{81-85}$ If oxygen is prescribed for patients with PAVMs, this should be based on symptoms, not $\mathrm{SaO}_{2}$ or $\mathrm{PaO}_{2}$ values. In the absence of coexisting cardiorespiratory disease or symptoms, there is no evidence that patients with PAVMs require supplemental oxygen during air travel. $^{82}$

Supplementary oxygen may be helpful for rare patients describing cardiorespiratory symptoms (usually in the setting of concurrent cardiac, respiratory or bone marrow disease) or neurological symptoms such as 'dizzy spells,' impaired cognition or other indicators of reduced cerebral oxygen delivery. ${ }^{80}$

iii) There is no indication for 'prophylactic' venesection for the asymptomatic PAVM patient with a high haematocrit. As for patients with cyanotic congenital heart disease, venesection (isovolaemic) should only be considered if there are symptoms of hyperviscosity.

Venesection risks include reducing arterial oxygen content (increasing cardiac demands and risks of cerebral ischaemia) and wider consequences from induced iron deficiency. ${ }^{13} 148687$ Hyperviscosity symptoms can be difficult to distinguish from the cerebral hypoperfusion symptoms that are more commonly reported by patients with PAVM-correlation of new symptoms with a newly increased haematocrit may help attribute them to hyperviscosity.

\section{B:Ischaemic stroke}

PAVM patients are at increased risk of ischaemic stroke and can be managed using antiplatelet agents, but the safety of thrombolysis is not established. A new stroke should prompt re-evaluation of both PAVM suitability for embolisation and development of other PAVM-specific stroke risk factors.

Ischaemic stroke risk appears broadly comparable across all sizes and severity of CT-evident PAVMs but is only minimally increased, if at all, by low grade contrast echo positive shunts without CT evidence of PAVMs. ${ }^{17} 1867$ In contrast to cerebral abscess (discussed below), there is little if any relationship with low $\mathrm{SaO}_{2} \cdot{ }^{17} 1880$ Only a small proportion of paradoxical emboli result in a clinical stroke ${ }^{18}$; however, several series emphasise the burden from silent infarcts. ${ }^{88} 89$ In one, $34 / 67$ (51\%) of patients with PAVMs had CT-evidence of cerebral infarcts at median age of 41 years. ${ }^{88}$ Symptoms suggesting an individual with PAVMs may be at higher risk of ischaemic stroke include previous typical symptoms of transient ischaemic attacks and frequent migraines. ${ }^{26}$ Both low serum iron and high fibrinogen are associated with ischaemic stroke and myocardial infarction, with risks potentially mediated by enhanced platelet aggregation. ${ }^{18} 90$ As in the general population, ${ }^{91}$ the majority of ischaemic strokes in patients with PAVM are treated with antiplatelet agents, which are generally tolerated well, even when HHT is present. ${ }^{49}$ Antiplatelet agents are currently used selectively based 
on symptoms and previous history of TIA or ischaemic stroke, but the indications may be extended. ${ }^{2689}$ Statins are also used as per standard stroke prevention guidance. ${ }^{91}$ Anticoagulants are rarely required for prevention of strokes due to PAVMs but may be required if there is concurrent atrial fibrillation or VTE. There is insufficient evidence of safety or clinical benefit to recommend thrombolysis.

\section{C:Brain abscess}

i) The possibility of brain abscess should be considered for PAVM patients presenting with acute neurological events, particularly in the setting of prolonged migraine-like headaches or epileptic fits.

ii) For patients with PAVMs, judicious dental hygiene is recommended, together with prophylactic antibiotics prior to dental, endoscopic, surgical and other interventional procedures that could lead to transient bacteraemias.

iii) There is an unexplained association between VTE and brain abscess. If patients with PAVMs are already in a prothrombotic state (eg, post-pneumonia), non-urgent dental treatment should be postponed until the acute phase response has resolved.

All patients with PAVMs are at potential risk of brain abscess, which causes death and substantial disability unless very promptly recognised and urgently referred for neurosurgical drainage. ${ }^{17-23}$ The risk of brain abscess is higher for patients with lower $\mathrm{SaO}_{2}$, prior VTE, iron loading ${ }^{17237}$ and may be higher in specific families. The majority of brain abscesses are caused by blood-borne dissemination of periodontal organisms, often following an initiating dental intervention. ${ }^{17} 222392$ Judicious dental hygiene is recommended to reduce post-toothbrushing ${ }^{93}$ and post-procedural ${ }^{94}$ bacteraemias and potential later reactivation of dormant bacteria. ${ }^{95}$ The use of prophylactic antibiotics prior to dental examinations and procedures is supported by a clinical trial indicating efficacy of intravenous and oral antibiotic regimes in limiting transient dental bacteraemias after tooth extractions ${ }^{94}$ and other guidance. ${ }^{96}$ Optimal regimens have not been established, but prior administration is recommended given that in the general population dental bacteraemias are cleared within minutes in the absence of antibiotics ${ }^{94}$ but prevented or resolved earlier with prior antibiotic administration. ${ }^{94}$ Based on earlier endocarditis guidance, oral administration is conventionally 1-2 hours before a procedure, with a further dose post-procedure. Coamoxiclav is the preferred agent ${ }^{9294}$ with clindamycin or metronidazole suggested for penicillin-allergic patients. Antibiotics are usually administered orally, but there may be particularly high-risk patients who have had prior abscesses for whom intravenous administration should be considered.

Purely non-dental microbes have also been isolated from PAVM-associated brain abscess, in some cases associated with a precipitating invasive procedure such as insertion of a venous line, epidural or gastrointestinal endoscope..$^{21-23}$ Skin procedures should therefore be performed with scrupulous aseptic technique, and antibiotic prophylaxis is recommended for procedures associated with transient bacteraemias such as endoscopy, surgery, embolisation and obstetric delivery.

\section{D:Iron deficiency and anaemia}

For hypoxaemic patients, iron supplementation may be required even if the haemoglobin is in the normal range. Microcytic and/ or hypochromic red cell indices suggest iron deficiency that is not excluded by a normal serum ferritin.

Clinicians should be vigilant to recognise 'relative' anaemia due to recent blood loss ${ }^{97}$ and/or iron deficiency, which is associated with an increased risk of ischaemic stroke, ${ }^{18} \mathrm{VTE}^{4798}$ and high output cardiac failure. ${ }^{43446}$ As a rough guide, to maintain a normal $\mathrm{CaO}_{2}$, an $\mathrm{SaO}_{2}$ of $90 \%$ requires a haemoglobin of $\geq 155 \mathrm{~g} / \mathrm{L}$ and an $\mathrm{SaO}_{2}$ of $80 \%$ requires a haemoglobin of $\geq 175 \mathrm{~g} / \mathrm{L}$. $^{1381}$

Although reduced haemoglobin may result from any conventional cause in patients with PAVM, the most common is iron deficiency because of underlying HHT. Serum iron and transferrin saturation index should be assessed in addition to ferritin, because ferritin is an acute phase protein and, as emphasised by recent NHS guidance, ${ }^{99}$ can be normal or high despite iron deficiency. ${ }^{4799100}$ Iron replacement is recommended if iron deficiency is confirmed. This may be due to the patient not meeting their recommended nutrient intake (RNI) $(8.7 \mathrm{mg} /$ day, or $14.8 \mathrm{mg}$ / day if a premenopausal female $\mathrm{e}^{101}$ ) or haemorrhage-adjusted iron requirement. ${ }^{40}$ Iron deficiency may also reflect substantially reduced gastrointestinal absorption of oral iron, for example, due to acute inflammatory states, ${ }^{102} 103$ co-ingestion of dietary inhibitors of absorption (particularly tea) $)^{104} 105$ or gastrointestinal-specific pathologies such as coeliac disease.

While iron deficiency requires treatment, care is required to minimise side effects that reduce compliance (particularly gastrointestinal ${ }^{40106}$ ) and/or increase iron demands ( $>5 \%$ of patients with HHT report increased nosebleeds following oral or intravenous iron $\left.{ }^{107}{ }^{108}\right)$. There are recent concerns of further HHT/ PAVM complications being aggravated through transient iron overload states after oral or intravenous iron. ${ }^{20} 23{ }^{109-111}$ In our experience, it is helpful to use oral iron supplements closer to the higher RNI (14.8 mg/day), such as ferrous gluconate $(35 \mathrm{mg}$ elemental iron $^{112}$ or even $14 \mathrm{mg}$ supplements), in preference to ferrous sulfate/fumarate preparations containing $\geq 65 \mathrm{mg}$ of elemental iron. Monitoring iron indices after commencing therapy (oral or intravenous) can also help reduce inadvertent iron toxicity through unnecessarily intense or prolonged use.

\section{E:Pregnancy}

The majority of PAVM pregnancies proceed normally even in the setting of significant hypoxaemia. However, there is a $1 \%$ risk of maternal death in pregnancy, and Anglo-French recommendations are therefore to manage these as 'high-risk' pregnancies involving a multiprofessional approach.

All patients should be aware of the increase in maternal mortality associated with PAVMs and/or underlying HHT. It is recommended that PAVMs are treated prior to conception. Patients with PAVM and their clinicians should be aware that any haemoptysis is potentially life threatening prompting immediate hospital admission and that antibiotic prophylaxis at delivery is required. ${ }^{23} 29113 \mathrm{SaO}_{2}$ commonly increases during pregnancy, despite interim growth of PAVMs: serial $\mathrm{CaO}_{2}$ values (incorporating haemoglobin) more accurately reflect PAVM status in this situation. ${ }^{73}$ Further pregnancy management details are available. ${ }^{29} 113$

\section{F:Pulmonary hypertension}

Significant pulmonary hypertension is rare in patients with PAVMs. The presence of pulmonary hypertension influences risk-benefit analyses for PAVM embolisation.

When present, pulmonary hypertension is usually due to high pulmonary blood flow secondary to hepatic AVMs (which may resolve following liver transplantation) and/or anaemia, and less commonly due to pulmonary arterial hypertension (particularly associated with ACVRL1/HHT2 pathogenic gene variants) or other aetiologies. ${ }^{53-55}$ Fatal increases in pulmonary artery 


\begin{tabular}{|c|c|c|}
\hline Topic & Subtopic & Summary \\
\hline 1. Embolisation & All & Refer all if technically feasible. \\
\hline \multirow{5}{*}{$\begin{array}{l}\text { 2. Medical management } \\
\text { (DIPPSSOH) }\end{array}$} & Iron & Treatment of iron deficiency may be required even if haemoglobin and ferritin in the normal range. \\
\hline & Pregnancy & Inform that pregnancies are designated 'high-risk', with a recent maternal death rate of $1 \%$. \\
\hline & Stroke & Thrombolysis is not recommended. Consider brain abscess. \\
\hline & Oxygen & Hypoxaemia is usually asymptomatic, and there is no indication for routine use of supplementary oxygen. \\
\hline & Pulmonary hypertension & Rare, usually due to hepatic AVMs/anaemia, and relative contraindication for embolisation. \\
\hline \multirow[t]{3}{*}{ 3. Assess/manage underlying $\mathrm{HHT}$} & General & Screening should be conducted only after informed, pretest counselling. \\
\hline & Cerebral AVMs & $\begin{array}{l}\text { While symptomatic patients should be investigated, based on current information, there appears to be only } \\
\text { a limited role for routine screening for cerebral AVMs in asymptomatic patients. }\end{array}$ \\
\hline & Hepatic AVMs & Screening of asymptomatic patients is not currently indicated. \\
\hline \multirow[t]{3}{*}{ 4. Follow-up } & CT use & $\begin{array}{l}\text { In view of radiation exposure, follow-up CT should only be performed on the basis of an informed clinical } \\
\text { decision. }\end{array}$ \\
\hline & Natural history & $\begin{array}{l}\text { Adults who have previously had a negative CT or contrast echocardiogram screen are unlikely to develop } \\
\text { pulmonary AVMs. }\end{array}$ \\
\hline & Post-embolisation & $\begin{array}{l}\text { Follow-up is recommended approximately } 6 \text { months after treatment to assess clinical, physiological and } \\
\text { radiological responses. }\end{array}$ \\
\hline
\end{tabular}

AVMs, arteriovenous malformations; $\mathrm{HHT}$, hereditary haemorrhagic telangiectasia.

pressure have been reported after PAVM embolisation, and severe pulmonary hypertension is considered a relative contraindication for this procedure. ${ }^{76}$ If pulmonary hypertension is suspected, then referral to a designated pulmonary hypertension service is recommended for further evaluation and management.

\section{G:Extra medical information}

Please see table 1. Patients can be advised that no modifications of normal activities are generally prescribed. Scuba divers should be informed that decompression illness ('the bends') is more common and severe in patients with pulmonary or cardiac rightto-left shunts. ${ }^{61114115}$

\section{SECTION 3: SCREENING, RECOGNITION, AND DIAGNOSIS 3A:PAVM screening}

Screening considerations include:

- All adult patients over 16 years with known or suspected HHT should be offered screening for PAVMs.

- A normal chest X-ray does not exclude clinically significant PAVMs, even if accompanied by normal oxygen saturations and no clinical symptoms.

- Either a negative thoracic CT scan (with or without contrast) or a negative contrast echocardiogram (CE), excludes clinically significant PAVMs.

- A positive CT scan is diagnostic for PAVMs, while CE is frequently positive for reasons unrelated to PAVMs.

- Although commonly recommended by international groups, we consider it is difficult to recommend $\mathrm{CE}$ as the preferred first-line screen as inexpert operators may miss clinically significant shunts. Thus, unless there is very strong local expertise in $\mathrm{CE}$, the preference is for the definite study to be by CT, but this decision should be approached on a caseby-case basis.
- CT scans should not be repeated based on protocol, given the potential radiation burden. However, there may be an indication to repeat post-pregnancy (a time of PAVM growth).

A recommendation for PAVM screening is indicated for an HHT patient with no symptoms attributable to the PAVMs, because of favourable risk-benefit considerations. ${ }^{116117}$ Screening recommendations should be made based on full consideration of all possible outcomes for the particular individual, including the possibility that screening may not directly benefit them and could potentially cause harm. ${ }^{116}$ The main risks of screening and treatment include radiation exposure (CT and angiography ${ }^{33}$ ), the possibility (although small) of precipitating a paradoxical embolic event or other treatment-related complication, potential discovery of an 'incidental' finding and psychological distress for a healthy person who could lose the perceived health benefits from an 'absence of a diagnosis'. 116

PAVM screening programmes aim to detect all clinically significant PAVMs. In the past, it was considered by some that all clinically significant PAVMs were detectable by chest X-ray and/ or low oxygenation indices, although data from 1996 emphasised such an approach risked missing smaller PAVMs of significance. ${ }^{118}$ An alternate view, based on the diameter of the smallest feeding artery to PAVM sacs, was then proposed as providing a cut-off for patients at greater risk of paradoxical embolic complications, and the ' $3 \mathrm{~mm}$ rule' was widely applied. In data from this period, many studies and clinical practices only reported PAVMs if they were above this size limit, making it difficult to interpret early screening literature. It became clear to specialists that chest X-ray, oxygenation and right-to-left shunts by $100 \%$ oxygen or ${ }^{99 \mathrm{~m}}$ technetium perfusion scans were insufficiently sensitive to rule out clinically significant PAVMs. ${ }^{8} 119120$ More recent cerebral abscess data have further emphasised the importance of smaller PAVMs, with cerebral abscesses commonly occurring 


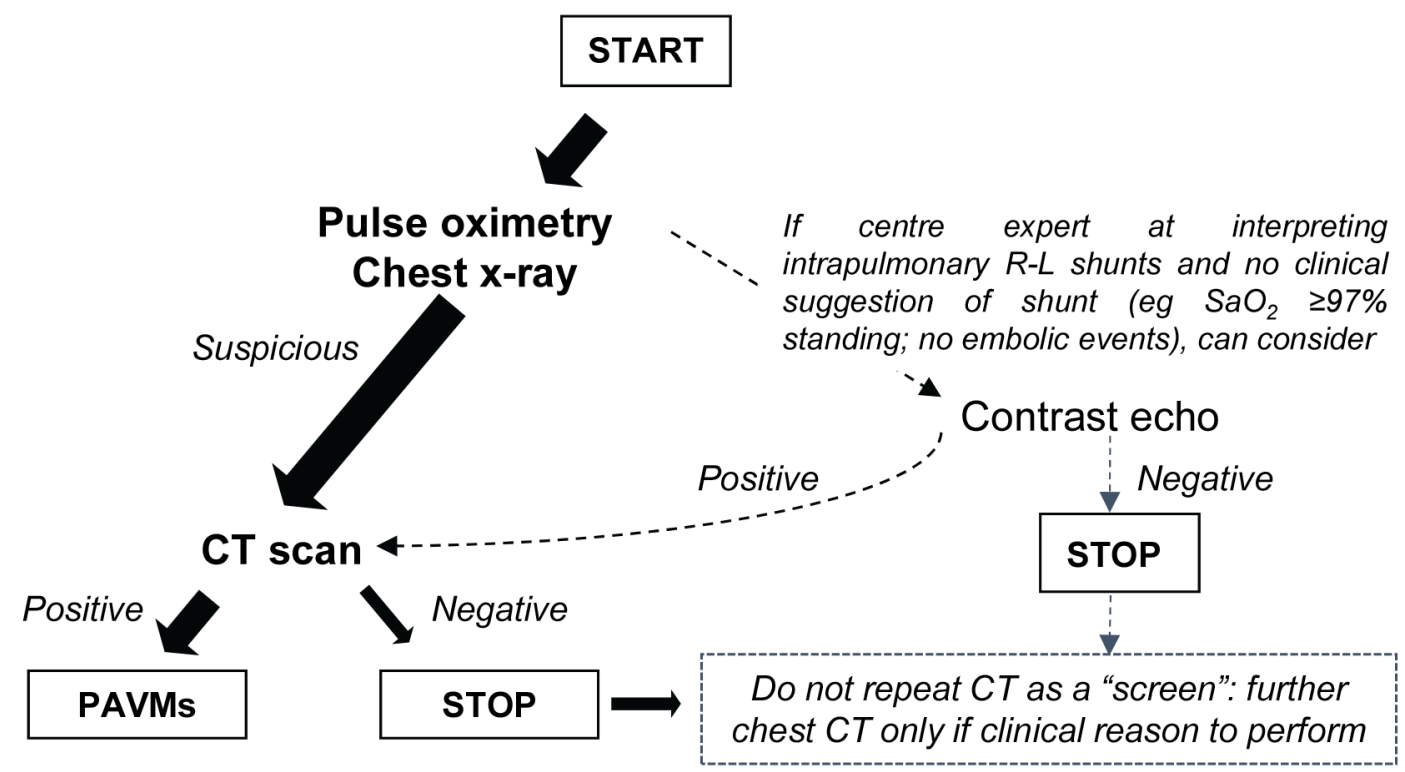

Figure 2 PAVM screening protocols in patients with known HHT. The historical development of PAVM screening practices is outlined in the text. Pulse oximetry $\left(\mathrm{SaO}_{2}\right.$ in the erect posture) is a simple method to evaluate shunt severity and usually made at 1 min intervals for 10 min with the mean of last four recordings used (see refs ${ }^{13}$ and 66 in which PAVM and control values are provided). Post-exercise $\mathrm{SaO}_{2}$ measurements do not appear to add sensitivity. ${ }^{118}$ A pre-treatment chest $\mathrm{X}$-ray is particularly helpful for later follow-up evaluations. Patients can be informed that if they are prone to migraines, that contrast-enhanced studies (including echocardiography), blood tests and MRI scans may provoke a migraine headache and are advised to bring migraine treatments with them. ${ }^{26} \mathrm{HHT}$, hereditary haemorrhagic telangiectasia; PAVMs, pulmonary arteriovenous malformations.

in patients with no respiratory symptoms and normal $\mathrm{SaO}_{2} \cdot{ }^{17} 23$ Moreover, of 65 consecutive UK cases of PAVM-associated cerebral abscess, in $14(21.5 \%)$ all PAVM feeding artery diameters were between 1 and $3 \mathrm{~mm} .{ }^{17} 23$

In efforts to limit unnecessary radiation exposure from screening CT scans, contrast echocardiography was developed as a method to exclude any right-to-left shunting. ${ }^{8} \mathrm{HHT}$ patients with a genuinely negative echocardiogram do not require a CT scan. However, there are two important provisos. First, a negative echocardiogram is unlikely if the patient has a low $\mathrm{PaO}_{2} /$ $\mathrm{SaO}_{2},{ }^{65}$ migraines, HHT1 $1^{121}$ or high cardiac output states. ${ }^{63} 64$ Low $\mathrm{SaO}_{2}$ values, particularly if these fall on standing (orthodeoxia), have higher specificity for subsequent demonstration of PAVMs than positive contrast echocardiography. ${ }^{120-122}$ Grading of shunt size has been used in attempt to identify positive CEs that do not require subsequent CT scans. ${ }^{121-125}$ Second, it should be noted that these are results from centres expert in the interpretation of intrapulmonary shunts in patients with HHT: methodological expertise and variability remains a major concern outside of such centres.

Figure 2 provides alternative PAVM screening protocols that can be used according to local expertise in evaluating intrapulmonary shunts by contrast echocardiography. We consider that radiation exposure is justifiable for a single screening scan, although a CT is more difficult to justify for an individual where PAVMs are identified on chest $\mathrm{X}$-ray, and they have no intention of having interventional treatment

\section{B:HHT screens for patients with PAVM}

The possibility of HHT should be considered in all patients with PAVMs, and sporadic aetiology only considered for single PAVMs. Details are beyond the scope of this text but briefly
- Screening for cerebral AVMs (which affects $\sim 10 \%$ of patients with HHT) should only be performed after consideration of the ARUBA trial and pretest counselling.

- Screening asymptomatic patients for hepatic and other systemic AVMs is not usually performed.

- Specialist management of other aspects of HHT (e.g., nosebleeds, iron deficiency anaemia and symptomatic AVMs) may be required.

- Where there is doubt about the clinical diagnosis, due to the importance of appropriately targeting cascade screening, HHT gene testing may be helpful.

A clinical diagnosis of HHT can be made in the presence of three out of four Curaçao criteria: (1) spontaneous recurrent epistaxis (nosebleeds), (2) mucocutaneous telangiectasia at characteristic sites, (3) a visceral manifestation (such as AVMs or gastrointestinal telangiectasia) and (4) an affected first-degree relative. ${ }^{126} 127$ Physicians should be aware that mucocutaneous telangiectasia are often subtle and that most patients will not volunteer a personal or family history of HHT or nosebleeds unless specifically asked.

Patients will often request screening for other AVMs based on earlier guidance and may be surprised by the current evidence base. Cerebral AVMs affect $\sim 10 \%$ of HHT patients. ${ }^{128}$ Guidelines published in $2011^{8}$ were generated in 2006 prior to publication of the ARUBA trial that demonstrated that based on the treatments available at that time, a bleed or other neurological sequelae were more likely if a cerebral AVM, which had not previously bled, was actively treated rather than if managed conservatively. ${ }^{129}$ The role for routine cerebral AVM screening for asymptomatic HHT patients is therefore not clear and a matter for informed patient choice. However, symptomatic patients deserve investigation and management according to conventional neurointerventional protocols. 
Recent hepatic AVM guidance ${ }^{130}$ confirms that screening is not indicated in asymptomatic patients and that in the small proportion of patients with hepatic AVMs who become symptomatic, medical management is often effective in relieving symptoms.

\section{C:Screening relatives of patients with PAVM}

i) For an individual with PAVMs due to HHT, a first-degree family member (i.e. parent, sibling or child) is at $\sim 1$ in 4 risk of PAVMs. This risk only falls to general population figures if the relative has a gene test excluding the HHT pathogenic gene variant ('mutation') present in the family.

ii) Unless the PAVM is solitary, and there is no suspicion of a hereditary vascular condition such as HHT, for an individual with PAVMs, clinical screening of their first-degree relatives is usually performed.

iii) HHT gene testing is available through a number of clinical genetic laboratories. In the past, this has focused on the major HHT genes (ENG, ACVRL1 and SMAD4). There is current discussion as to the extent gene panels should be expanded to include other genes.

For an individual with PAVMs due to HHT, a first-degree family member (eg, parent, sibling and child) is at $\sim 1$ in 4 risk of PAVMs. This risk rises to $\sim 1$ in 2 if HHT is known to be present in the relative. The figures are modified slightly by which HHT gene contains the pathogenic DNA variant ('mutation'): PAVMs affect $>50 \%$ of ENG and SMAD4 HHT cases and a lower proportion of ACVRL1 (ALK-1) cases. ${ }^{39}$ For an individual with PAVMs and HHT, a blood relative's risk of PAVMs is exceedingly small if HHT is excluded in that relative. However, exclusion of HHT is difficult on clinical grounds alone due to the late onset penetrance of HHT so that it may remain subclinical at the time of screening. Therefore, HHT can only be reliably excluded in a blood relative if they do not have the causal (pathogenic) gene variant for their specific family.

For an individual with PAVMs and no other features of HHT, care must be taken in case the PAVM(s) are due to otherwise subclinical HHT or an alternate hereditary vasculopathy. At present, clinical screening of first-degree relatives is usually performed, unless the PAVM is solitary, and there is no clinical or molecular suspicion of a hereditary vascular condition such as HHT.

HHT gene testing is available through a number of clinical genetic laboratories. With three major genes already identified for HHT-associated PAVMs (ENG, ACVRL1 and SMAD4), cost-effectiveness considerations have already led to the introduction of next-generation panel-based sequencing. These genes are unlikely to encompass the full range of hereditary predisposition to PAVMs as the full spectrum of hereditary vasculopathies associated with PAVMs is not yet known and awaits information from whole-genome sequencing initiatives particularly those specifically recruiting PAVM patients without a causal HHT gene variant (eg, the 100,000 Genomes Project ${ }^{131}$ ).

\section{SECTION 4: FOLLOW UP}

\section{A: Limited indications for follow-up CT scan}

In view of radiation exposure, we consider that there is no place for routine follow-up CT. A repeat CT may be indicated if there is clinical suspicion of the development or increase in size of PAVMs. This may be based on symptoms, pulse oximetry, chest $\mathrm{X}$-ray, right-to-left shunt evaluations by contrast echocardiography or the clinical scenario, for example, after pregnancy.

While CT-based follow-up strategies provide precise anatomical data, ${ }^{132} 133$ the incremental benefit over radiation-sparing strategies has not been established. Protocol-driven radiation exposure is high, ${ }^{33}$ and it is unclear if this is the reason for an apparent excess of breast cancers in HHT. ${ }^{34}$ Further evidence is awaited to evaluate the proportion of increasing right-to-left shunts ${ }^{124125}$ that are due to PAVM enlargement/growth compared with non-PAVM causes such as intrapatient variability, exercise, anaemia or other causes of high output states. ${ }^{42-46} 63-65125$ Due to the basal predominance of PAVMs, right-to-left shunting commonly increases on standing, ${ }^{134}$ reflected by orthodeoxia and exuberant orthostatic tachycardia. ${ }^{66}$

\section{B: Patients with a negative initial screen}

Adult patients who have had a negative screen for pulmonary AVMs (whether the CE was positive or negative) are at low risk of developing pulmonary AVMs later in life. Due to growth and development of PAVMs in teenage years, children who had a negative PAVM screen require a repeat screen in adult life.

For adults, the main purpose of follow-up is to evaluate patients for the development of any additional symptoms (that may be HHT-related) and/or to provide updated advice. The need for a follow up assessment may be triggered by a referral from non-respiratory clinical services or directly as a result of patient concerns.

\section{C: Recently embolised patients}

i) Patients with pulmonary AVMs that have been recently embolised or resected are recommended to have follow-up approximately 6 months after treatment to assess clinical, physiological $\left(\mathrm{SaO}_{2}, \mathrm{Hb}\right.$ and $\left.\mathrm{CaO}_{2}\right)$ and radiological responses.

ii) Radiological evaluation should be by chest $\mathrm{X}$-ray (compared with the pre-embolisation film) unless there is a specific clinical reason to request a further CT scan. In patients where PAVMs are visible on chest X-ray pre-treatment, a repeat film will usually demonstrate resolution of the treated PAVM sacs, thus a post-treatment CT is usually unnecessary.

iii) It should be assumed that untreated small residual PAVMs are present requiring ongoing antibiotic prophylaxis and any prior stroke prevention strategies (e.g., antiplatelet agents), unless all radiographically visible PAVMs were obliterated at the time of embolisation and the patient is in the small group who have a negative CE. The chest X-ray can be falsely reassuring in this setting as it does not exclude small PAVMs.

If PAVM closure is achieved, gas exchange improves immediately post-embolisation, while haematological and haemodynamic compensations are lost over weeks to months. Regression of most PAVM sacs, dilated feeding arteries and draining veins occurs over 3-6 months, ${ }^{2-413} 1516$ 68-72 and there is usually evidence of this on PA or lateral chest X-rays. However, the majority of treated patients will have a degree of residual disease (see 4D), and this will likely be below the limit of resolution by chest X-ray. Contrast echocardiography will remain positive unless there has been complete obliteration of all angiographically visible PAVMs and is not routinely indicated post-embolisation. Failure of PAVM sacs/draining veins to regress on chest X-ray may indicate reperfusion or recanalisation ${ }^{72}$ and need for more detailed imaging and intervention. For further follow-up, see Section 4D.

\section{D: Further follow-up for patients with residual or untreated pulmonary AVMs}

i) All patients require a holistic approach to follow-up. This may be offered with a combination of primary or secondary care, depending on specific clinical circumstances and local expertise.

ii) Patients with evidence of residual or untreated pulmonary AVMs, and their primary care team, should remain aware of all medical management issues (see Section 2). 
iii) Patients with ongoing symptoms, or where there is clinical concern, should remain under regular PAVM specialist review, in order to optimise medical and potential further interventional management.

The majority of patients will be asymptomatic and may be followed up in primary care with input from specialist centres. ${ }^{77}$ Additional primary and secondary care-targeted education is helpful to emphasise the importance of avoiding or promptly treating iron deficiency, maintaining antibiotic prophylaxis regimes and recognising symptoms of concern (see below). General practitioners should be informed that patients will not be eligible for standard dental, anaemia, pregnancy and stroke management pathways and that specialist advice or review may be required at times of intercurrent surgery, pregnancy or acute medical events.

Specialised review may be required for patients who develop new symptoms such as dyspnoea, fatigue, haemoptysis, increasingly severe migraines, palpitations or heart failure. New onset haemoptysis in a previously treated patient should raise the possibility of haemorrhage arising from PAVM sacs persisting post-embolisation with an acquired systemic arterial collateral blood supply. ${ }^{12} 135136$ Prompt discussion with radiologists, and aortic phase-enhanced thoracic CT scanning is indicated.

There is no strong evidence to support any particular protocol for follow-up. ${ }^{1373124125}$ In patients deemed to require follow-up, an approach using clinical symptoms, lying/standing $\mathrm{SaO}_{2}$, chest radiograph and blood tests may be useful. CEs will remain positive, and it is not currently clear that there is value in repeating these studies. A post-pregnancy CT can be helpful, however if there has been no symptomatic change, radiation exposure can be limited by waiting until after families are completed.

Acknowledgements We would like to thank Dr James Jackson and Dr Maneesh Patel, and those who provided comments as part of the public consultation period for their critical review of the manuscript. The assistance of the BTS Standards of Care Committee is gratefully acknowledged.

Contributors CLS was lead author and responsible for the content overall. RC, JWD, DGK and SJW reviewed, modified and approved all sections of the document. All authors agreed the final submission.

Disclaimer A Clinical Statement reflects the expert views of a group of specialists who are well versed on the topic concerned and who carefully examine the available evidence in relation to their own clinical practice. A Clinical Statement does not involve a formal evidence review and is not developed in accordance with clinical practice guideline methodology. Clinical Statements are not intended as legal documents or a primary source of detailed technical information. Readers are encouraged to consider the information presented and reach their own conclusions.

Competing interests The authors have completed declarations of interest forms in line with the BTS policy, and forms are available from BTS Head Office.

Provenance and peer review Not commissioned, externally peer reviewed.

(c) Article author(s) (or their employer(s) unless otherwise stated in the text of the article) 2017. All rights reserved. No commercial use is permitted unless otherwise expressly granted.

\section{REFERENCES}

1 Shovlin CL. Pulmonary arteriovenous malformations. Am J Respir Crit Care Med 2014;190:1217-28.

2 Gill SS, Roddie ME, Shovlin CL, et al. Pulmonary arteriovenous malformations and their mimics. Clin Radiol 2015;70:96-110.

3 Lacombe P, Lacout A, Marcy PY, et al. Diagnosis and treatment of pulmonary arteriovenous malformations in hereditary hemorrhagic telangiectasia: an overview. Diagn Interv Imaging 2013;94:835-48.

4 Woodward CS, Pyeritz RE, Chittams JL, et al. Treated pulmonary arteriovenous malformations: patterns of persistence and associated retreatment success. Radiology 2013:269:919-26.

5 Nakayama M, Nawa T, Chonan T, et al. Prevalence of pulmonary arteriovenous malformations as estimated by low-dose thoracic CT screening. Intern Med 2012;51:1677-81.
6 Guttmacher AE, Marchuk DA, White RI, et al. Hereditary hemorrhagic telangiectasia. N Engl J Med 1995;333:918-24.

7 Shovlin CL, Guttmacher AE, Buscarini E, et al. Diagnostic criteria for hereditary hemorrhagic telangiectasia (Rendu-Osler-Weber syndrome). Am J Med Genet 2000;91:66-7.

8 Faughnan ME, Palda VA, Garcia-Tsao G, et al. International guidelines for the diagnosis and management of hereditary haemorrhagic telangiectasia. J Med Genet 2011;48:73-87.

9 Shovlin CL. Hereditary haemorrhagic telangiectasia: pathophysiology, diagnosis and treatment. Blood Rev 2010:24:203-19.

10 Shovlin CL, Gossage JR. Pulmonary arteriovenous malformations: evidence of physician under-education. ERJ Open Res. 2017:3:00104-2016.

11 Donaldson JW, McKeever TM, Hall IP, et al. The UK prevalence of hereditary haemorrhagic telangiectasia and its association with sex, socioeconomic status and region of residence: a population-based study. Thorax 2014;69:161-7.

12 Shovlin CL, Jackson JE. Pulmonary arteriovenous malformations and other pulmonary-vascular abnormalities. In: Mason B, Murray N, eds. Murray and Nadel's textbook of respiratory medicine. 6th edn. Pennsylvania: ElsevierSaunders, 2015.

13 Santhirapala V, Williams LC, Tighe HC, et al. Arterial oxygen content is precisely maintained by graded erythrocytotic responses in settings of high/normal serum iron levels, and predicts exercise capacity: an observational study of hypoxaemic patients with pulmonary arteriovenous malformations. PLoS One 2014:9:e90777.

14 Yasuda W, Jackson JE, Layton DM, et al. Hypoxaemia, sport and polycythaemia: a case from Imperial College London. Thorax 2015:70:601-3.

15 Howard L, Santhirapala V, Murphy K, et al. Cardiopulmonary exercise testing demonstrates maintenance of exercise capacity in patients with hypoxemia and pulmonary arteriovenous malformations. Chest 2014;146:709-18.

16 Vorselaars VM, Velthuis S, Mager JJ, et al. Direct haemodynamic effects of pulmonary arteriovenous malformation embolisation. Neth Heart J 2014;22:328-33.

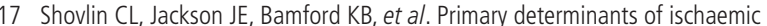
stroke/brain abscess risks are independent of severity of pulmonary arteriovenous malformations in hereditary haemorrhagic telangiectasia. Thorax 2008;63:259-66.

18 Shovlin CL, Chamali B, Santhirapala V, et al. Ischaemic strokes in patients with pulmonary arteriovenous malformations and hereditary hemorrhagic telangiectasia: associations with iron deficiency and platelets. PLoS One 2014;9:e88812.

19 Clark K, Pyeritz RE, Trerotola SO. Angina pectoris or myocardial infarctions, pulmonary arteriovenous malformations, hereditary hemorrhagic telangiectasia, and paradoxical emboli. Am J Cardiol 2013;112:731-4.

20 Shovlin CL, Awan I, Cahilog Z, et al. Reported cardiac phenotypes in hereditary hemorrhagic telangiectasia emphasize burdens from arrhythmias, anemia and its treatments, but suggest reduced rates of myocardial infarction. Int I Cardiol 2016;215:179-85.

21 Kjeldsen AD, Tørring PM, Nissen $\mathrm{H}$, et al. Cerebral abscesses among Danish patients with hereditary haemorrhagic telangiectasia. Acta Neurol Scand 2014;129:192-7.

22 Mathis S, Dupuis-Girod S, Plauchu H, et al. Cerebral abscesses in hereditary haemorrhagic telangiectasia: a clinical and microbiological evaluation. Clin Neurol Neurosurg 2012:114:235-40.

23 Boother EJ, Brownlow S, Tighe HC, et al. Cerebral abscess associated with odontogenic bacteremias, hypoxemia, and iron loading in immunocompetent patients with right-to-left shunting through pulmonary arteriovenous malformations. Clin Infect Dis 2017:595-603.

24 Post MC, Thijs V, Schonewille WJ, et al. Embolization of pulmonary arteriovenous malformations and decrease in prevalence of migraine. Neurology 2006:66:202-5.

25 Elphick A, Shovlin CL. Relationships between epistaxis, migraines, and triggers in hereditary hemorrhagic telangiectasia. Laryngoscope 2014;124:1521-8.

26 Patel T, Elphick A, Jackson JE, et al. Injections of intravenous contrast for computerized tomography scans precipitate migraines in hereditary hemorrhagic telangiectasia subjects at risk of paradoxical emboli: implications for right-to-left shunt risks. Headache 2016;56:1659-63.

27 Ference BA, Shannon TM, White RI, et al. Life-threatening pulmonary hemorrhage with pulmonary arteriovenous malformations and hereditary hemorrhagic telangiectasia. Chest 1994;106:1387-90.

28 Cottin V, Gamondes D, Schuller A, et al. Near-fatal haemorrhage from pulmonary arteriovenous malformation in HHT with increased cardiac output. Eur Respir Rev 2009;18:190-2

29 Shovlin CL, Sodhi V, McCarthy A, et al. Estimates of maternal risks of pregnancy for women with hereditary haemorrhagic telangiectasia (Osler-Weber-Rendu syndrome): suggested approach for obstetric services. BJOG 2008;115:1108-15.

30 Gupta S, Faughnan ME, Bayoumi AM. Embolization for pulmonary arteriovenous malformation in hereditary hemorrhagic telangiectasia: a decision analysis. Chest 2009:136:849-58.

31 Hsu CC, Kwan GN, Thompson SA, et al. Embolisation for pulmonary arteriovenous malformation. Cochrane Database Syst Rev 2012:8:CD008017.

32 Donaldson JW, McKeever TM, Hall IP, et al. Complications and mortality in hereditary hemorrhagic telangiectasia: a population-based study. Neurology 2015;84:1886-93. 
33 Hanneman K, Faughnan ME, Prabhudesai V. Cumulative radiation dose in patients with hereditary hemorrhagic telangiectasia and pulmonary arteriovenous malformations. Can Assoc Radiol J 2014;65:135-40.

34 Hosman AE, Devlin HL, Silva BM, et al. Specific cancer rates may differ in patients with hereditary haemorrhagic telangiectasia compared to controls. Orphanet J Rare Dis 2013:8:195.

35 McDonald J, Wooderchak-Donahue W, VanSant Webb C, et al. Hereditary hemorrhagic telangiectasia: genetics and molecular diagnostics in a new era. Front Genet 2015;6:1.

36 Govani FS, Giess A, Mollet IG, et al. Directional next-generation RNA sequencing and examination of premature termination codon mutations in endoglin/hereditary haemorrhagic telangiectasia. Mol Syndromol 2013;4:184-96.

37 Jelsig AM, Tørring PM, Kjeldsen AD, et al. JP-HHT phenotype in Danish patients with SMAD4 mutations. Clin Genet 2016;90:55-62.

38 Cottin V, Plauchu H, Bayle JY, et al. Pulmonary arteriovenous malformations in patients with hereditary hemorrhagic telangiectasia. Am J Respir Crit Care Med 2004:169:994-1000.

39 Letteboer TG, Mager JJ, Snijder RJ, et al. Genotype-phenotype relationship in hereditary haemorrhagic telangiectasia. J Med Genet 2006;43:371-7.

40 Finnamore $\mathrm{H}$, Le Couteur J, Hickson M, et al. Hemorrhage-adjusted iron requirements, hematinics and hepcidin define hereditary hemorrhagic telangiectasia as a model of hemorrhagic iron deficiency. PLoS One 2013;8:e76516.

41 Mehta PA, Dubrey SW. High output heart failure. QJM 2009;102:235-41.

42 Anand IS, Chandrashekhar Y, Ferrari R, et al. Pathogenesis of oedema in chronic severe anaemia: studies of body water and sodium, renal function, haemodynamic variables, and plasma hormones. Br Heart J 1993;70:357-62.

43 Hébert PC, Van der Linden P, Biro G, et al. Physiologic aspects of anemia. Crit Care Clin 2004:20:187-212.

44 Porter WB, James GW. The heart in anemia. Circulation 1953;8:111-6.

45 Shovlin CL. Circulatory contributors to the phenotype in hereditary hemorrhagic telangiectasia. Front Genet 2015;6:101

46 Buscarini $\mathrm{E}$, Leandro $\mathrm{G}$, Conte $\mathrm{D}$, et al. Natural history and outcome of hepatic vascular malformations in a large cohort of patients with hereditary hemorrhagic teleangiectasia. Dig Dis Sci 2011;56:2166-78.

47 Livesey JA, Manning RA, Meek JH, et al. Low serum iron levels are associated with elevated plasma levels of coagulation factor VIII and pulmonary emboli/deep venous thromboses in replicate cohorts of patients with hereditary haemorrhagic telangiectasia. Thorax 2012;67:328-33.

48 Shovlin CL, Sulaiman NL, Govani FS, et al. Elevated factor VIII in Hereditary Haemorrhagic Telangiectasia (HHT): association with venous thromboembolism Thromb Haemost 2007;98:1031-9.

49 Devlin HL, Hosman AE, Shovlin CL. Antiplatelet and anticoagulant agents in hereditary hemorrhagic telangiectasia. N Eng/ J Med 2013;368:876-8.

50 Duarte CW, Black AW, Lucas FL, et al. Cancer incidence in patients with hereditary hemorrhagic telangiectasia. J Cancer Res Clin Oncol 2017;143:209-14.

51 Hosman AE, Shovlin CL. Cancer and hereditary haemorrhagic telangiectasia. J Cancer Res Clin Oncol 2017;143:369-70.

52 Duarte CW, Murray K, Lucas FL, et al. Improved survival outcomes in cancer patients with hereditary hemorrhagic telangiectasia. Cancer Epidemiol Biomarkers Prev 2014:23:117-25.

53 Girerd B, Montani D, Coulet F, et al. Clinical outcomes of pulmonary arterial hypertension in patients carrying an ACVRL1 (ALK1) mutation. Am J Respir Crit Care Med 2010;181:851-61.

54 Vorselaars VM, Velthuis S, Snijder RJ, et al. Pulmonary hypertension in hereditary haemorrhagic telangiectasia. World J Cardiol 2015;7:230-7.

55 Sopeña B, Pérez-Rodríguez MT, Portela D, et al. High prevalence of pulmonary hypertension in patients with hereditary hemorrhagic telangiectasia. Eur J Intern Med 2013;24:e30-4.

56 Latchford AR, Neale K, Phillips RK, et al. Juvenile polyposis syndrome: a study of genotype, phenotype, and long-term outcome. Dis Colon Rectum 2012;55:1038-43.

57 Heald B, Rigelsky C, Moran R, et al. Prevalence of thoracic aortopathy in patients with juvenile polyposis syndrome-hereditary hemorrhagic telangiectasia due to SMAD4. Am J Med Genet A 2015;167A:1758-62.

58 Kopf GS, Laks H, Stansel HC, et al. Thirty-year follow-up of superior vena cavapulmonary artery (Glenn) shunts. J Thorac Cardiovasc Surg 1990;100:662-70.

59 Agnoletti G, Borghi A, Annecchino FP, et al. Regression of pulmonary fistulas in congenital heart disease after redirection of hepatic venous flow to the lungs. Ann Thorac Surg 2001;72:909-11.

60 Larsson ES, Solymar L, Eriksson BO, et al. Bubble contrast echocardiography in detecting pulmonary arteriovenous malformations after modified Fontan operations. Cardiol Young 2001;11:505-11.

61 Smart D, Mitchell S, Wilmshurst $\mathrm{P}$, et al. Joint position statement on persistent foramen ovale (PFO) and diving. South Pacific Underwater Medicine Society (SPUMS) and the United Kingdom Sports Diving Medical Committee (UKSDMC). Diving Hyperb Med 2015;45:129-31.

62 Krowka MJ, Fallon MB, Kawut SM, et al. International liver transplant society practice guidelines: diagnosis and management of hepatopulmonary syndrome and portopulmonary hypertension. Transplantation 2016;100:1440-52.
63 Romac R, Barak O, Glavas D, et al. Characterization of blood flow through intrapulmonary arteriovenous anastomoses and patent foramen ovale at rest and during exercise in stroke and transient ischemic attack patients. Echocardiography 2017;34:676-82

64 Laurie SS, Elliott JE, Goodman RD, et al. Catecholamine-induced opening of intrapulmonary arteriovenous anastomoses in healthy humans at rest. J Appl Physiol 2012;113:1213-22.

65 Duke JW, Davis JT, Ryan BJ, et al. Decreased arterial PO2, not 02 content, increases blood flow through intrapulmonary arteriovenous anastomoses at rest. J Physiol 2016;594:4981-96.

66 Santhirapala V, Chamali B, McKernan H, et al. Orthodeoxia and postural orthostatic tachycardia in patients with pulmonary arteriovenous malformations: a prospective 8-year series. Thorax 2014:69:1046-7.

67 Velthuis S, Buscarini E, van Gent MWF, et al. Grade of pulmonary right-to-left shunt on contrast echocardiography and cerebral complications: a striking association. Chest 2013;144:542-8.

68 Pollak JS, Saluja S, Thabet A, et al. Clinical and anatomic outcomes after embolotherapy of pulmonary arteriovenous malformations. J Vasc Interv Radiol 2006:17:35-45

69 Hart JL, Aldin Z, Braude P, et al. Embolization of pulmonary arteriovenous malformations using the Amplatzer vascular plug: successful treatment of 69 consecutive patients. Eur Radiol 2010;20:2663-70.

70 Letourneau-Guillon L, Faughnan ME, Soulez G, et al. Embolization of pulmonary arteriovenous malformations with amplatzer vascular plugs: safety and midterm effectiveness. J Vasc Interv Radiol 2010;21:649-56.

71 Remy J, Remy-Jardin M, Wattinne L, et al. Pulmonary arteriovenous malformations: evaluation with $\mathrm{CT}$ of the chest before and after treatment. Radiology 1992:182:809-16.

72 Trerotola SO, Pyeritz RE. Does use of coils in addition to amplatzer vascular plugs prevent recanalization? AJR Am J Roentgenol 2010;195:766-71.

73 Rizvi A, Macedo P, Babawale L, et al. Hemoglobin Is a vital determinant of arterial oxygen content in hypoxemic patients with pulmonary arteriovenous malformations. Ann Am Thorac Soc 2017:14:903-11.

74 Donaldson JW. The epidemiology of hereditary haemorrhagic telangiectasia and pulmonary arteriovenous malformations (PhD thesis). Nottingham, University of Nottingham, 2016. http://eprints.nottingham.ac.uk/etheses/.

75 Shovlin CL, Tighe HC, Davies RJ, et al. Embolisation of pulmonary arteriovenous malformations: no consistent effect on pulmonary artery pressure. Eur Respir J 2008:32:162-9

76 Shovlin CL, Gibbs JS, Jackson JE. Management of pulmonary arteriovenous malformations in pulmonary hypertensive patients: a pressure to embolise? Eur Respir Rev 2009:18:4-6.

77 European Reference Network. The European Reference Network for Vascular Diseases (VASCERN) HHT WG. https://vascern.eu/expertise/rare-diseases-wgs/hhtwg/ (accessed 21 May 2017)

78 Chick JFB, Reddy SN, Pyeritz RE, et al. A survey of pulmonary arteriovenous malformation screening, management, and follow-up in hereditary hemorrhagic telangiectasia centers of excellence. Cardiovasc Intervent Radiol 2017:40:1003-9.

79 Pierucci P, Murphy J, Henderson KJ, et al. New definition and natural history of patients with diffuse pulmonary arteriovenous malformations: twenty-seven-year experience. Chest 2008;133:653-61.

80 Shovlin CL, Buscarini E, Hughes JMB, et al. Long-term outcomes of patients with pulmonary arteriovenous malformations considered for lung transplantation, compared with similarly hypoxaemic cohorts. BMJ Open Respir Res 2017;4:e000198.

81 Pittman RN. Oxygen transport. In: Regulation of tissue oxygenation. San Rafael, CA: Morgan \& Claypool Life Sciences, 2011

82 Mason CG, Shovlin CL. Flight-related complications are infrequent in patients with hereditary haemorrhagic telangiectasia/pulmonary arteriovenous malformations, despite low oxygen saturations and anaemia. Thorax 2012:67:80-1.

83 Whyte MK, Hughes JM, Jackson JE, et al. Cardiopulmonary response to exercise in patients with intrapulmonary vascular shunts. J Appl Physiol 1993;75:321-8.

84 Evans AM, Hardie DG, Peers C, et al. Hypoxic pulmonary vasoconstriction: mechanisms of oxygen-sensing. Curr Opin Anaesthesiol 2011;24:13-20.

85 Sommer N, Strielkov I, Pak O, et al. Oxygen sensing and signal transduction in hypoxic pulmonary vasoconstriction. Eur Respir J 2016;47:288-303.

86 McMullin MF, Bareford D, Campbell P, et al. General haematology task force of the british committee for standards in haematology. Guidelines for the diagnosis, investigation and management of polycythaemia/erythrocytosis. $\mathrm{Br} J$ Haematol 2005;130:174-95.

87 Van de Pette JE, Guthrie DL, Pearson TC. Whole blood viscosity in polycythaemia: the effect of iron deficiency at a range of haemoglobin and packed cell volumes. $\mathrm{Br} J$ Haematol 1986:63:369-75.

88 Moussouttas M, Fayad P, Rosenblatt M, et al. Pulmonary arteriovenous malformations: cerebral ischemia and neurologic manifestations. Neurology 2000:55:959-64.

89 Fatania G, Patel MC, Jackson JE, et al. Burden of cerebral infarcts identified by screening cerebral MRI scans in patients with pulmonary arteriovenous malformations. Thorax (Abstract) 2017. In press 
90 Woods HF, Youdim MBH, Boullin D, et al. Monoamine metabolism and platelet function in iron-deficiency anaemia. In: Iron metabolism. Amsterdam: Elsevier, 1977:227-48.

91 Royal College of Physicians Intercollegiate Stroke Working Party. National clinical guideline for stroke. 4th edn, 2012. https://www.rcplondon.ac.uk/guidelines-policy/ stroke-guidelines.

92 Shovlin C, Bamford K, Wray D. Post-NICE 2008: antibiotic prophylaxis prior to dental procedures for patients with pulmonary arteriovenous malformations (PAVMs) and hereditary haemorrhagic telangiectasia. Br Dent J 2008;205:531-3.

93 Tomás I, Diz P, Tobías A, et al. Periodontal health status and bacteraemia from daily oral activities: systematic review/meta-analysis. J Clin Periodontol 2012;39:213-28.

94 Limeres Posse J, Álvarez Fernández M, Fernández Feijoo J, et al. Intravenous amoxicillin/clavulanate for the prevention of bacteraemia following dental procedures: a randomized clinical trial. J Antimicrob Chemother 2016;71:2022-30.

95 Damgaard C, Magnussen K, Enevold C, et al. Viable bacteria associated with red blood cells and plasma in freshly drawn blood donations. PLoS One 2015;10:e0120826.

96 Habib G, Lancellotti P, Antunes MJ, et al. 2015 ESC Guidelines for the management of infective endocarditis: The task force for the management of infective endocarditis of the European Society of Cardiology (ESC). Endorsed by: European Association for Cardio-Thoracic Surgery (EACTS), the European Association of Nuclear Medicine (EANM). Eur Heart J 2015;36:3075-128.

97 Roked F, Jackson JE, Fuld J, et al. Pulmonary thromboemboli modifying the natural history of pulmonary arteriovenous malformations. Am J Respir Crit Care Med 2011;183:828-9.

98 Bang S-M, Lee J-O, Kim YJ, et al. Anemia and activities of daily living in the Korean urban elderly population: results from the Korean Longitudinal Study on Health and Aging (KLoSHA). Ann Hematol 2013;92:59-65.

99 NICE. NICE Clinical Knowledge Summaries (CKS): Interpreting ferritin levels. http:// cks.nice.org.uk/anaemia-iron-deficiency\#! diagnosissub:3 (accessed Aug 2016).

100 Valberg LS. Plasma ferritin concentrations: their clinical significance and relevance to patient care. Can Med Assoc J 1980;122:1240-8

101 Department of Health. Dietary reference values for food energy and nutrients for the United Kingdom. London: HMSO, 1991.

102 Coffey R, Ganz T. Iron homeostasis: an anthropocentric perspective. J Biol Chem 2017;292:12727-34.

103 Nemeth E, Ganz T. Anemia of inflammation. Hematol Oncol Clin North Am 2014;28:671-81.

104 Finnamore HE, Whelan K, Hickson M, et al. Top dietary iron sources in the UK. Br J Gen Pract 2014;64:172-3.

105 Nelson M, Poulter J. Impact of tea drinking on iron status in the UK: a review. J Hum Nutr Diet 2004;17:43-54.

106 Hallberg L, Ryttinger L, Sölvell L. Side-effects of oral iron therapy. A doubleblind study of different iron compounds in tablet form. Acta Med Scand Supp/ 1966;459:3-10.

107 Shovlin CL, Gilson C, Busbridge M, et al. Can iron treatments aggravate epistaxis in some patients with hereditary hemorrhagic telangiectasia? Laryngoscope 2016:126:2468-74.

108 Shovlin CL, Patel T, Jackson JE. Embolisation of PAVMs reported to improve nosebleeds by a subgroup of patients with hereditary haemorrhagic telangiectasia. ERJ Open Res 2016;2:00035-2016

109 Duchini A, Sfeir HE, Klachko DM. Hemochromatosis work up. 2016 http://emedicine. medscape.com/article/177216-workup (accessed 8 Jan 2017).

110 Chamali B, Finnamore $H$, Manning R, et al. Dietary supplement use and nosebleeds in hereditary haemorrhagic telangiectasia - an observational study. Intractable Rare Dis Res 2016;5:109-13

111 Mollet IG, Patel D, Govani FS, et al. Low dose iron treatments induce a DNA damage response in human endothelial cells within minutes. PLoS One 2016;11:e0147990.

112 NICE. Clinical Knowledge Summaries (CKS): treating iron deficinecy anemia. https:// cks.nice.org.uk/anaemia-iron-deficiency\#! scenariorecommendation:6 (accessed 21 May 2017).

113 de Gussem EM, Lausman AY, Beder AJ, et al. Outcomes of pregnancy in women with hereditary hemorrhagic telangiectasia. Obstet Gynecol 2014;123:514-20.
114 Wilmshurst PT, Pearson MJ, Walsh KP, et al. Relationship between right-to-left shunts and cutaneous decompression illness. Clin Sci 2001:100:539-42.

115 Shovlin CL, Wilmshurst P, Jackson JE. Pulmonary arteriovenous malformations and other pulmonary aspects of hereditary haemorrhagic telangiectasia. Eur Respir Mon 2011;54:218-45.

116 Wilson JMG, Jungner G. The principles and practice of screening for disease. Geneva: World Health Organization; 1968, Public Health Papers No: 34.

117 Raffle A, Gray M. Screening evidence and practice. Oxford: Oxford University Press, 2007.

118 Thompson RD, Jackson J, Peters AM, et al. Sensitivity and specificity of radioisotope right-left shunt measurements and pulse oximetry for the early detection of pulmonary arteriovenous malformations. Chest 1999;115:109-13.

119 Mager JJ, Zanen P, Verzijlbergen F, et al. Quantification of right-to-left shunt with $(99 \mathrm{~m}) \mathrm{Tc}$-labelled albumin macroaggregates and $100 \%$ oxygen in patients with hereditary haemorrhagic telangiectasia. Clin Sci 2002;102:127-34.

120 Shovlin CL, Jackson JE, Hughes JMB. et a/Pulmonary arteriovenous malformations and other pulmonary vascular disorders. In: Mason RJ, Broaddus C V, Murray JF, ; eds. Murray and Nadel's textbook of respiratory medicine. 4th Edn. Philadelphia: Elsevier Saunders, 2005:1480-501.

121 van Gent MW, Post MC, Snijder RJ, et al. Real prevalence of pulmonary right-to-left shunt according to genotype in patients with hereditary hemorrhagic telangiectasia: a transthoracic contrast echocardiography study. Chest 2010;138:833-9.

122 Velthuis S, Buscarini E, Mager JJ, et al. Predicting the size of pulmonary arteriovenous malformations on chest computed tomography: a role for transthoracic contrast echocardiography. Eur Respir J 2014;44:150-9.

123 Parra JA, Cuesta JM, Zarrabeitia R, et al. Screening pulmonary arteriovenous malformations in a large cohort of Spanish patients with hemorrhagic hereditary telangiectasia. Int J Cardio/ 2016:218:240-5.

124 Vorselaars VM, Velthuis S, Snijder RJ, et al. Follow-up of pulmonary right-to-left shunt in hereditary haemorrhagic telangiectasia. Eur Respir J 2016;47:1750-7.

125 Chinet T. How to follow-up patients with hereditary haemorrhagic telangiectasia and suspected pulmonary arteriovenous malformations. Eur Respir J 2016:47:1618-21.

126 Shovlin CL, Guttmacher AE, Buscarini E, et al. Diagnostic criteria for hereditary hemorrhagic telangiectasia (Rendu-Osler-Weber syndrome). Am J Med Genet 2000;91:66-7.

127 van Gent MW, Velthuis S, Post MC, et al. Hereditary hemorrhagic telangiectasia: how accurate are the clinical criteria? Am J Med Genet A 2013;161A:461-6.

128 Brinjikji W, lyer VN, Yamaki V, et al. Neurovascular manifestations of hereditary hemorrhagic telangiectasia: a consecutive series of 376 patients during 15 Years. AJNR Am J Neuroradiol 2016;37:1479-86

129 Mohr JP, Parides MK, Stapf C, et al. Medical management with or without interventional therapy for unruptured brain arteriovenous malformations (ARUBA): a multicentre, non-blinded, randomised trial. Lancet 2014;383:614-21.

130 European Association for the Study of the Liver. EASL clinical practice guidelines: vascular diseases of the liver. J Hepatol 2016;64:179-202.

131 Genomics England. Rare disease eligibility criteria. https://www.genomicsengland. co.uk/information-for-gmc-staff/rare-disease-documents/rare-disease-eligibilitycriteria/ (accessed 21 May 2017).

132 Gamondès D, Si-Mohamed S, Cottin V, et al. Vein diameter on unenhanced multidetector CT predicts reperfusion of pulmonary arteriovenous malformation after embolotherapy. Eur Radiol 2016;26:2723-9.

133 Bélanger C, Chartrand-Lefebvre C, Soulez G, et al. Pulmonary arteriovenous malformation (PAVM) reperfusion after percutaneous embolization: sensitivity and specificity of non-enhanced CT. Eur J Radio/ 2016;85:150-7.

134 Ueki J, Hughes JM, Peters AM, et al. Oxygen and 99mTc-MAA shunt estimations in patients with pulmonary arteriovenous malformations: effects of changes in posture and lung volume. Thorax 1994;49:327-31.

135 Sagara K, Miyazono N, Inoue H, et al. Recanalization after coil embolotherapy of pulmonary arteriovenous malformations: study of long-term outcome and mechanism for recanalization. AJR Am J Roentgenol 1998;170:727-30.

136 Brillet PY, Dumont P, Bouaziz N, et al. Pulmonary arteriovenous malformation treated with embolotherapy: systemic collateral supply at multidetector CT angiography after 2-20-year follow-up. Radiology 2007:242:267-76 